\title{
Syringomyelia affecting the entire spinal cord secondary to primary spinal intramedullary central nervous system lymphoma
}

\author{
IVAN LANDAN, JOHN GILROY, DAVID E WOLFE \\ From the Wayne State University School of Medicine, Detroit, Michigan, USA
}

SUMMARY A case of syringomyelia involving the entire spinal cord secondary to a spinal intramedullary tumour is described. Cerebrospinal fluid cytology and microscopic evaluation of gross necropsy specimens revealed a primary large cell lymphoma of the central nervous system. In addition there was massive leptomenigeal lymphomatosis involving the cortex, brainstem, and cerebellum. No solitary intracranial mass lesion was found.

Primary central nervous system lymphoma is a rare disease. This type of tumour has been given a variety of different names. ${ }^{1-3}$ An intracranial solitary mass lymphoma is much more common than primary spinal lesions. Helle et $a l^{4}$ reviewed 40 cases and only one had spinal cord involvement. Henry et $a l^{5}$ found spinal cord lymphomas in only four out of 81 cases.

\section{Case report}

A 37 year old right handed female was first seen in August 1984 with a progressive paraparesis. Her problems first began in January 1982 when she started experiencing intermittent mid-thoracic back pain associated with occipital headache. In August 1982 she started to drag her left leg as she walked and developed occasional tingling of her left lower limb. Six months later she noted urinary frequency and abdominal muscle spasms with progressive left leg weakness. By September 1983 she was confined to a wheelchair because of unsteadiness of gait. In April 1984 she developed urinary retention and subsequently learned self catheterisation. Over the next few months she began to have right leg weakness and bilaterally lumbar radicular pains radiating into lower limbs. On 25 July 1984 she reported

Address for reprint requests: Dr Ivan Landan, M.D., Wayne State University School of Medicine, Department of Neurology, University Health Center, 4201 St. Antoine - 6E Detroit, Michigan 48201, USA.

Received 10 October 1986 and in revised form 26 February 1987. Accepted 28 February 1987 numbness of all four extremities and the following day developed respiratory distress and asystole requiring mechanical respiratory support. This was followed by rapid development of a quadriplegia.

Neurologic examination revealed normal mental status; the cranial nerves were intact with the exception of paralysis of the sternocleidomastoids and trapezeii. She had a flaccid quadriparesis with complete sensory loss below $\mathrm{C} 2$.

Cerebrospinal fluid examination of 28 July 1984 revealed protein $34.86 \mathrm{~g} / \mathrm{l}$, glucose $0 \cdot 14 \mathrm{~g} / \mathrm{l}$, IgG $2 \cdot 5 \mathrm{~g} / \mathrm{l}, \quad \mathrm{RBC}$ $915 / \mathrm{mm}^{3}$, WBC $233 /^{3}$ (99\%neutrophils). The VDRL was negative, bacterial fungal and viral cultures were negative. No tumour cells were seen. A cisternal tap on 31 July 1984 revealed protein $0.52 \mathrm{~g} / \mathrm{l}$, glucose $0.95 \mathrm{~g} / \mathrm{l}, \mathrm{RBC} 403 / \mathrm{mm}^{3}$, WBC $28 / \mathrm{mm}^{3}$, (70\% neutrophils). The fluid was xanthochromic in both examinations. The patient's SMA 12, electrolytes, and sedimentation rate were normal. A myelogram with computed tomography of the spinal cord was performed with metrizamide enhancement and demonstrated a syrinx cavity extending from $\mathrm{C} 2$ to the conus medullaris. On 1 August 1984 a cervical laminectomy and myelotomy was performed.

The patient continued to be quadriplegic, and ventilator dependent. Tracheostomy was performed on 9 August 1984; she suffered from multiple urinary tract, blood, skin and lung infections accompanied by progressive anaemia. Her mentation was normal until May 1985 when she became progressively disoriented and confused. At that time, computed tomography revealed hydrocephalus without evidence of mass lesion or haemorrhage. A ventriculoperitoneal shunt was inserted and the patient's mentation improved significantly. She remained alert until 12 June 1985 when she developed vertigo and complained of hallucinations. On 18 


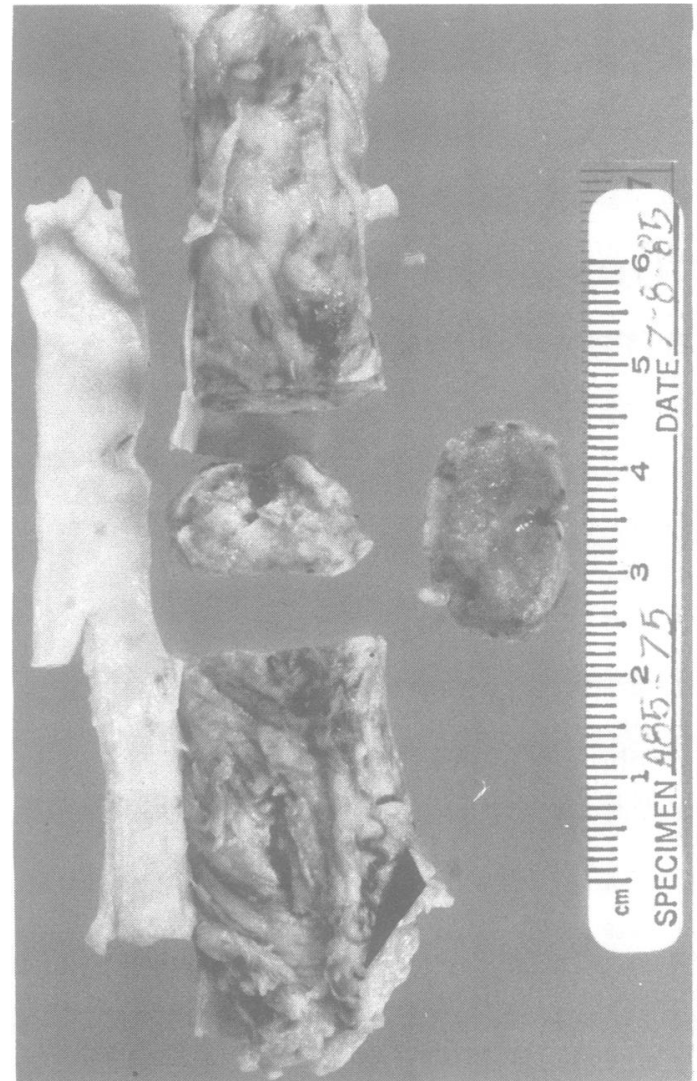

Fig Gross specimen of spinal cord showing replacement of normal anatomy with tumour cells.

June 1985 she developed focal and generalised status epilepticus resulting in coma. The EEG of 20 June 1985 was consistent with a burst suppression pattern.

Cerebrospinal fluid examination on 18 June 1985 revealed a CSF glucose of $0.67 \mathrm{~g} / 1$ and a protein of $0.33 \mathrm{~g} / 1$ with evidence of "malignant" cells in the CSF. The cell count was $298 / \mathrm{mm}^{3}$ red cells, 6 white cells and 20 lymphocytes. IgG was again elevated. By 27 June 1985 the patient had absent brainstem reflexes and the EEG was consistent with electrical status epilepticus. The patient showed no signs of cerebral or brainstem function on 7 July 1985 when she expired after a cardiac arrest.

The necropsy revealed paravertebral lymph nodes consistent with lymphoma. There was tumour destruction of the body of the second lumbar vertebra and infiltration of the psoas muscles. Neuropathological examination revealed a fixed brain weight of $1450 \mathrm{~g}$. The cranial dura was normal except for the shunt hole. There was no evidence of herniation. The central areas of the diencephalon, brainstem and cerebellum were necrotic. The undersurface of the forebrain, particularly around the optic chiasm, lateral fissures, and uncii of both temporal lobes, showed a whitish appearance consistent with leptomeningeal lymphomatosis.

The spinal cord was two and one half times its normal diameter at all levels and showed diffuse myelomalacia and central syrinx formation. The cord was grossly necrotic and the nerve roots and cauda equina were encased by tumour. The microscopic sections revealed neoplasm at multiple levels with a necrotic cord and not a single structure could be identified which resembled normal cord parenchyma. The pathology was that of primary large cell lymphoma.

\section{Discussion}

Syringomyelia may be defined as a chronic progressive degenerative disease characterised by cavitation of the spinal cord. It has been described with various spinal cord tumours ${ }^{6-8}$ including haemangioblastoma, ${ }^{9}$ meningioma, ${ }^{1011}$ astrocytoma, spongioblastoma, ependymoma, neurolemmoma, oligodendroglioma, and teratoma. The syrinx may occur in the cervical thoracic, or lumbar cord and rarely at the conus medullaris. ${ }^{10}$

A literature search revealed no prior case report of primary CNS lymphoma with primarily spinal involvement resulting in syringomyelia of the entire cord. Malignant lymphomas of the CNS usually involve brain tissue as single or multiple avascular mass lesions. ${ }^{4512-14}$ There is a high incidence of CNS lymphoma in patients with systemic lupus erythematosus $^{15}$ and patients receiving immunosuppressive therapy for renal transplant. ${ }^{16}$

This patient showed no evidence of immunosuppression, a condition usually present in patients with CNS lymphoma. ${ }^{514}$ Only one case was found in the literature of spinal lymphoma without intracranial involvement. Bruni et al ${ }^{17}$ reported an intramedullary primary lymphoma involving $\mathrm{Cl}$ to $\mathrm{T} 1$. Their patient had no evidence of syringomyelia and there was no leptomeningeal lymphomatosis. Two cases have been reported of leptomeningeal lymphomatosis of the cord secondary to solitary intracranial lymphomas. ${ }^{213}$ Mitsumoto et al ${ }^{12}$ reported a case of primary spinal intramedullary lymphoma who later developed a solitary intracranial mass.

The most common myelographic abnormality in CNS lymphoma is segmental cord widening ${ }^{17-19}$ extending over four or five segments. In many cases the myelogram was normal and the cord widening was only appreciated at necropsy. In institutions where magnetic resonance scanning is unavailable the diagnostic test of choice is the delayed CT metrizamide study. ${ }^{20}$

All reported cases of spinal lymphoma in the literature have described a solid tumour. With this in mind it is intriguing to speculate on the development of a syrinx in the present case. Perhaps it was due to the longer survival of the patient owing to advances in respirator care, and it may be that this is the natural course of the disease given time. This would require 
necrosis of the centrally located tumour with liquefaction followed by absorption of necrotic tissue.

The most common CSF findings in all series reviewed was an elevated CSF protein followed by mononuclear pleocytosis. Henry et al ${ }^{5}$ reviewed CSF findings in 41 cases in which 35 were abnormal. Of these 35 , all had CSF protein greater than $0.6 \mathrm{~g} / 1$ and 14 had a lymphocytosis. Helle et $a l^{4}$ reviewed the CSF findings in nine patients, of whom seven had elevated CSF protein while only four had a mononuclear lymphocytosis.

Isolation of lymphoma cells is seen in less than half of all cases. ${ }^{21} 22$ Of the 52 cases reviewed by Helle $e t$ $a l,{ }^{4}$ only $15(29 \%)$ were positive for neoplastic cells. As in our case, this was seen in advanced stages of the disease after several negative examinations. Elevation of serum IgG was seen in this case and others in the literature. ${ }^{1423}$ Kawakani et al ${ }^{14}$ performed immunoglobulin testing in 19 cases, of which 11 had elevated IgG, and nine had elevated IgM. The combination of CSF lymphocytosis elevated CSF protein and IgG is frequently seen in multiple sclerosis, the diagnosis this patient carried for 2 years. In the present case and other series ${ }^{121719}$ the initial signs were both motor and sensory. Papilloedema was absent, though it has been seen in cervical intramedullary tumours. ${ }^{24}$ Bladder symptoms and radicular pains are reported in this case and were present in other cases.

Advances in intensive care of patients who are ventilator dependent is prolonging life in severely debilitated patients and it is quite likely that more cases of diffuse spinal cord damage will be seen in the future. A high degree of clinical suspicion must be present to make the diagnosis since there are no pathognomonic signs.

\section{References}

1 Russel DS, Rubinstein LJ. Pathology of Tumors of the Nervous System, 4th ed. London: E Arnold 1977:101-15.

2 Rubinstein LJ. Tumors of the Central Nervous System, Sect. III, Fasc. 8: Washington: Armed Forces Institute of Pathology 1966.

3 Reznick M. Pathology of primary reticulum cell sarcomas of the human nervous system. Acta Neuropathol (Berlin) 1975;6(suppl):91-4.

4 Helle TL, Britt RH, Colby TV. Primary lymphomas of the central nervous system. J Neurosurg 1984;60: 94-103.

5 Henry JM, Heffner RR, Dillard SH, Earle KM, David RI. Primary malignant lymphomas of the central nervous system. Cancer 1974;34:1292-1302.
6 Vinken PJ, Bruyn GW. Tumors of the spine and spinal cord. Handbook of Clinical Neurology-Vol. 19, 20. Amsterdam: North Holland 1984:326-7, 8-9, 112-28.

7 Chandler WF, Johnson JH Jr. Syringomyelia presenting as a mass lesion of the conus medullaris. Surg Neurol 1979;12(5):385-8.

8 Kiwak KJ, Deroy MJ, Shields WD. Torticollis in three children with syringomyelia and spinal cord tumor. Neurology 1983;33:946-8.

9 Enomoto H, Shibata T, Ito A, Haroda T, Satake T. Multiple hemangioblastomas accompanied by syringomyelia. Surg Neurol 1984;22:197-203.

10 Blaylock PL. Hydrosyringomyelia of conus medullaris associated with a thoracic meningioma. $J$ Neurosurg 1981;54:833-5.

11 Hirata Y, Matsukado Y, Kaku M. Syringomyelia associated with a foramen magnum meningioma. Surg $\mathrm{Neu}$ rol 1985;23:291-4.

12 Mitsumoto $\mathrm{H}$, Brever AC, Lederman RJ. Malignant lymphoma of the central nervous system. A case of primary spinal intramedullary involvement. Cancer 1980;46:1258-62.

13 Sorger K. Reticulum cell sarcoma of the central nervous system. Can Med Assoc J 1963;89:503-7.

14 Kawakami Y, Tabuchi K, Ohnishi R, Asari S, Nishimoto A. Primary central nervous system lymphoma. J Neurosurg 1985;62:522-27.

15 Lipsmeyer EA. Development of malignant cerebral lymphoma in a patient with systemic lupus erythematosus treated with immunosuppression. Arthritis Rheum 1972;15:183-6.

16 Cho ES, Connolly E, Porro RS. Primary reticulum cell sarcoma of the brain in a renal transplant recipient. J Neurosurg 1974;41:235-9.

17 Bruni J, Bilbao JN, Gary T. Primary intramedullary malignant lymphoma of the spinal cord. Neurology 1977;27:896-8.

18 Hautzer NW, Aiyesimoju A, Robitaille Y. "Primary" spinal intramedullary lymphomas, a review. Ann Neurol 1982;14:62-6.

19 Fisher RG. Intramedullary lymphoma of the spinal cord. Neurosurgery 1979;5:270-2.

20 Kan S, Fox AJ, Vinuela F, Banett HJ, Peerless SJ. Delayed CT metrizamide enhancement of syringomyelia secondary to tumor. $A J N R$ 1983;4:73-8.

21 Jellinger K, Radaskiewicz TH, Slowik F. Primary malignant lymphomas of the central nervous system in man. Acta Neuropathol 1975;Suppl 6:95-102.

22 Littman P, Wang CC. Reticulum cell sarcoma of the brain. A review of the literature and a study of 19 cases. Cancer 1975;35:1414-20.

23 Houthoff HJ, Poppema S, Ebels EJ, et al. Intracranial malignant lymphomas. A morphologic and immunocytologic study of 20 cases. Acta Neuropathol (Berl) 1978;44:203-10.

24 Sloof JL, Kernohan JW, McCarty CS. Primary Intramedullary Tumors of the Spinal Cord and Filum Terminale. London: WB Saunders, 1964. 